\title{
Survey data analysis of the related risk factors of echinococcosis in Inner Mongolia of China and Mongolia
}

\author{
Shengbin Zhang ${ }^{1}$, Zhelin Yun*1, Erdengsuhe $\mathrm{E}^{2}$, Baoqin Liu ${ }^{1}$ \\ ${ }^{1}$ Department of Hepatobiliary Surgery, Baogang Hospital, Baotou, Inner Mongolia, China \\ ${ }^{2}$ Mongolian Hospital, Erenhot, China
}

Received: February 1, 2019

Accepted: March 7, 2019

Online Published: March 10, 2019

DOI: $10.5430 /$ dcc.v6n1p17

URL: https://doi.org/10.5430/dcc.v6n1p17

\begin{abstract}
Objective: The aim of the study is to analyze the risk factors of hepatic echinococcosis in mass epidemiological studies in Inner Mongolia of China and Mongolia and provide a basis for related authorities to make appropriate preventive measures.

Methods: Eight areas in Inner Mongolia and Zamyn-Üüd region of Mongolia were selected as epidemiological fields. By distributing epidemiological questionnaires to local residents and performing serological examinations and abdominal ultrasound examinations, the data results were collected and analyzed to obtain the risk factors.

Results: In this research, there were 7,373 cases of valid data in the area of Inner Mongolia and 1,500 cases in the area of Mongolia. The mean age of the whole survey samples was $52.86 \pm 13.90$, and the ratio of the female $(58.35 \%)$ was much higher than that of the male $(41.65 \%)$. Both univariate analysis and multivariate analysis in this study showed that the female (14.7\%) had a higher risk of hepatic echinococcosis than the male (10.9\%). From the perspective of profession, children, educators and medical personnel had a lower incidence, herdsmen had the highest positive rate of the disease (15.8\%). Living in pastoral areas, having been to pastoral areas, eating uncooked food and drinking unboiled water, raising dogs and surrounding activities of foxes and voles can also increase the risk of positivity.

Conclusions: Our findings demonstrate that the most important risk factor of hepatic echinoccosis is unhealthy lifestyles and customs in farmers and herdsmen. It is possible to provide a basis for related authorities to make effective protective measures aiming at hepatic echinococcosis.
\end{abstract}

Key Words: Hepatic echinococcosis, Epidemiological study, Inner Mongolia of China, Mongolia

\section{INTRODUCTION}

Echinococcosis is a common zoonotic parasitosis in the pastoral and the farming-pastoral regions. ${ }^{[1]}$ It is made up of cystic echinococcosis (CE) and alveolar echinococcosis (AE). Echinococcus granulosus can induce $\mathrm{CE}$ in humans, and echinococcus multilocularis can lead to AE. Echinococcus granulosus is distributed worldwide, and echinococcus multilocularis is only distributed in the Northern Hemisphere. They are main pathogens which cause human diseases. Mongolia, along with the pastoral region in Inner Mongolia of our country, is the affected area of echinococcosis. ${ }^{[2-4]}$ Western China is a high-prevalence area of echinococcosis. Ac-

\footnotetext{
*Correspondence: Zhelin Yun; Email: yunzhelin727@ 126.com; Address: Department of Hepatobiliary Surgery, Baogang Hospital, Baotou, Inner Mongolia 014010, China.
} 
cording to a survey, the infection rate of echinococcosis in humans is $3.1 \%-31.5 \%$, with the prevalence ranging from $0.5 \%$ to $5.0 \%$. For herdsmen and farmers, this type of disease is the main reason of "falling into poverty for illness". [5] However, the current therapeutic options are very limited, especially for hepatic alveolar echinococcosis. This type of disease shows concealed clinical symptoms and a malignant tendency. Therefore, it is of great harm to human health. Most of patients with hepatic alveolar echinococcosis accompanying obstructive jaundice are found to be in the terminal stage of disease when they admit to the hospital. At this time, the lesions have invaded important great vessels of the liver and biliary tract, so that there is no opportunity to make a radical operation ${ }^{[6]}$ and it is urgent to seek for proper solutions. Hence, it is imperative to make a specific analysis of the epidemiological characteristics and risk factors of hepatic echinococcosis to establish corresponding prevention and treatment measures. Even though some current researches have revealed conceivable risk factors and behaviors for the prevalence of echinococcosis, ${ }^{[7-9]}$ there is no large sample study with regard to the population in Inner Mongolia of China and Mongolia. Based on 8,873 cases of related data in the epidemiological study of hepatic echinococcosis in this region, this research is designed to analyze the risk behaviors of hepatic echinococcosis and explore the risk factors in Inner Mongolia and Mongolia respectively, providing an epidemiological evidence to establish appropriate prevention and treatment measures of hepatic echinococcosis.

\section{OBJECTS AND METHODS}

\subsection{Survey sites and respondents}

Inner Mongolia Autonomous Region, located in the north of our country, has an overall area of $1,180,000 \mathrm{~km}^{2}$. It is one of the most important bases of animal husbandry. The prairies, the area of which accounts for $50 \%$ of the overall area, are distributed in 8 leagues and cities. Echinococcosis is a serious parasitosis which is prevalent in the pastoral area of Inner Mongolia Autonomous Region, and it is also the main cause which leads to the poverty in farmers and herdsmen and impedes the development of local economy. Cluster sampling was applied to this research on the basis of geographical position and economic status, i.e., epidemiological survey sites of echinococcosis were selected designedly and systematically in the pastoral and the farming-pastoral regions in the east, the middle, the west and the north of Inner Mongolia. Erenhot, Sonid Left Banner, Sonid Right Banner, Dongsheng, Baotou, Wuhai, Alxa and Hulun Buir were surveyed in Inner Mongolia. In addition, Zamyn-Üüd region was surveyed in Mongolia. Zamyn-Üüd is a frontier town in the southeast of Mongolia, and it is $550 \mathrm{~km}$ away from Ulan
Bator, the capital of Mongolia. Besides, Zamyn-Üüd is adjacent to Erenhot, with a population of no more than 10,000 and a backward in economy. Most of herdsmen raise dogs and livestock, take domestic slaughter as the conventional slaughter manner, and feed dogs with abandoned livestock offals. This lifestyle makes people susceptible to echinococcosis. In the earlier stage, the survey team mainly focused on site visit for the epidemiological study, which was started officially in 2012 and lasted for 4 years. By cooperating with local centers for disease control and hospitals, the team executed the sampling survey aiming at residents above 5 years old, which were given physical examinations at home or in hospital. All respondents were given questionnaire survey, hepatic ultrasound examinations and serological examinations. The questionnaire covers general information (such as name, gender, nationality, religion, profession, degree of education, living pattern, raising livestock or not and slaughter manner) and epidemiological profile for hepatic echinococcosis (including working or living in the pastoral area or not, contacting with livestock, diet, past medical history and treatment condition) in detail.

\subsection{Diagnostic methods of echinococcosis}

\subsubsection{Serological examination for echinococcosis}

$2 \mathrm{ml}$ of blood was taken from each case of respondent by use of blood collection tube. After autoagglutination, the blood sample was centrifuged at the rotate speed of 4,000 $\mathrm{r} / \mathrm{min}$ for $5 \mathrm{~min}$, with the serum taken and placed at $-80^{\circ} \mathrm{C}$. ELISA was used to measure the level of IgG antibody to echinococcosis in the respondent's serum, with the positive rate of antibodies considered as the infection rate of echinococcosis. All detection reagents are ELISA kits (made by Haitai Biopharmaceutical Co., Ltd.) of IgG antibody to echinococcosis. The registration number of ELISA kit is GXZZ 20153400132, the specification is 98 potions/box, and the sensitivity is $100 \%$. The principle is that the kit is made up of a microplate coated with purified echinococcosis antigens, enzyme conjugate of monoclonal antibody IgG and other types of reagents. The principle of ELISA is applied to the detection of IgG antibody level to echinococcosis in human serum, with the advantage of rapidly determining whether people are infected by hepatic echinococcosis antigens. Nevertheless, the limitation of this method is that it is necessary to diagnose the type of hepatic echinococcosis with the help of imageological examinations.

\subsubsection{Ultrasound examination for echinococcosis}

Portable B-mode ultrasound system was used to perform the abdominal scan to determine whether hydatid cysts existed in the liver. The examination result was required to be recorded in the following way: $1=$ Normal (including CE patients 
without relapse and patients with normal B-mode image); 2 $=\mathrm{CE}$ (including $\mathrm{CE}$ patients with relapse after surgery); 3 $=\mathrm{AE} ; 4=$ Suspected (including patients with calcification more than $1 \mathrm{~cm}) ; 5=$ Isolated calcification; $6=$ Other abnormal images (such as gallstones an so on). The carriage rate of hydatid cysts was considered as the infection rate of echinococcosis.

\subsection{Statistical analysis}

SPSS 19.0 software was applied to statistical analysis in this research, continuous data were represented by means \pm standard deviation $(\bar{X} \pm \mathrm{s})$, the enumeration data was represented by frequency and percentage, with $t$-test applied to the comparison between the positive group and the negative group and the comparison of continuous data fitted to normal distribution. Rank sum test was used in the comparison of non-normally distributed data and ranked data. Pearson chi-square test was performed to the categorical data, with backward-stepwise regression adopted in multivariate analysis. Univariate analysis and multivariate analysis were performed with stratified analysis (in view of Inner Mongolia of China and Mongolia) taking into consideration. All tests were two-sided tests, and the difference $p<.05$ was considered to be of statistical significance.

\section{RESUlts}

\subsection{Prevalence and positive rate through serological ex- amination}

In Inner Mongolia, 7,373 cases of respondents were given serological examinations, 869 cases showed positive results, and the positive rate was $11.7 \%$; in Zamyn-Üüd of Mongolia, 1,500 cases of respondents were given serological examinations, 311 cases showed positive results, and the positive rate was $20.7 \%$. According to B-mode ultrasound examination, in Inner Mongolia, 5 cases of patients were found to have CE, 103 cases showed suspected results, and the positive rate was 1.46\%; in Zamyn-Ü̈üd of Mongolia, 25 cases were found to be with $\mathrm{CE}$ and 1 case with $\mathrm{AE}, 68$ cases showed suspected results, and the positive rate was $6.27 \%$ (see Table 1). It followed that ultrasound examination result was far more different from serological examination result, and the reason may be that blood samples collected in the pastoral area were required to be taken to the experimental center for detection, so that the positive rate by means of serological examination was increased correspondingly due to long geographical span and distance, repeated freezing and thawing of blood samples and man-made factors in the detection.

Table 1. The results of B-mode ultrasound and serological examinations in the population of two regions

\begin{tabular}{llllll}
\hline \multirow{2}{*}{ Region } & \multirow{2}{*}{} & \multicolumn{3}{c}{ B-mode ultrasound examination } & Serological examination \\
\cline { 3 - 6 } & & $\mathbf{C E}$ & $\mathbf{A E}$ & Suspected & Positive (\%) \\
\hline Inner Mongolia & 7,373 & 5 & 0 & 103 & $869(11.7)$ \\
Mongolia (Zamyn-Üüd) & 1,500 & 25 & 1 & 68 & $311(20.7)$ \\
\hline
\end{tabular}

\subsection{Basic characteristics of the population}

7,373 cases of valid data in Inner Mongolia were included in this research, with 1,500 cases in Mongolia. See Table 2 for details. The mean age of the whole survey samples was $52.86 \pm 13.90$, the percentage of the female $(58.35 \%)$ was higher than that of the male $(41.65 \%)$.

Table 2. Basic characteristics of the population

\begin{tabular}{llll}
\hline Region & Sample size & Age & $\begin{array}{l}\text { The percentage } \\
\text { of female (\%) }\end{array}$ \\
\hline Inner Mongolia & 7,373 & $54.87 \pm 13.03$ & 57.3 \\
Baotou & 201 & $59.44 \pm 11.85$ & 53.7 \\
Alxa & 2,182 & $52.39 \pm 13.64$ & 60.3 \\
Dongsheng & 1,300 & $53.89 \pm 12.27$ & 56.2 \\
Sonid Left Banner & 750 & $53.15 \pm 13.40$ & 55.2 \\
Hulun Buir & 381 & $48.79 \pm 12.51$ & 63.7 \\
Wuhai & 929 & $54.24 \pm 13.16$ & 48.5 \\
Sonid Right Banner & 1,630 & $60.97 \pm 10.27$ & 59.3 \\
Mongolia (Zamyn-Üüd) & 1,500 & $42.92 \pm 13.79$ & 63.4 \\
\hline
\end{tabular}

Published by Sciedu Press

\subsection{Univariate analysis}

The overall analysis in view of Inner Mongolia and Mongolia showed that there was no statistically significant difference in the comparison in the age of positive respondents (53.31 $\pm 14.01)$ and negative respondents $(52.80 \pm 13.88)$. The percentage of female with positive results $(14.7 \%)$ was obviously higher than that of males $(10.9 \%)$. The positive rates of different professions were shown in Figure 1 (house maids and slaughter house workers were classified into the item "others" due to the few amount of cases). Not only the overall positive rate, but also the positive rates of different professions in Mongolia were higher than those in Inner Mongolia. From the perspective of profession, children, educators and medical personnel in Inner Mongolia showed a lower incidence, and herdsmen showed the highest positive rate. In Mongolia, the positive rate in farmers reached up to $50 \%$, and the positive rate in children was $30 \%$. The comparison in the positive rate in different nationalities showed that people 
of Zang and Han nationalities had a lower positive rate, but people of Man nationality had the highest positive rate (see Figure 2). However, as people of Han and Mongolia nationalities accounted for a higher percentage, the results about people of other nationalities were considered to be worthless. Generally, the incidence in people of Mongolia nationality was higher than people of Han nationality. In the case of living pattern, the incidence in nomadic people was higher than that in people who settled and who settled in winter and nomadic in summer. Raising livestock, contacting with dogs in the pastoral area, having neighborhood who were raising dogs, having fox furs, domestic slaughter of livestock, burying or burning abandoned offals from sick livestock or feeding dogs with them could significantly increase the risk of hepatic echinococcosis. See Table 3 for specific results.

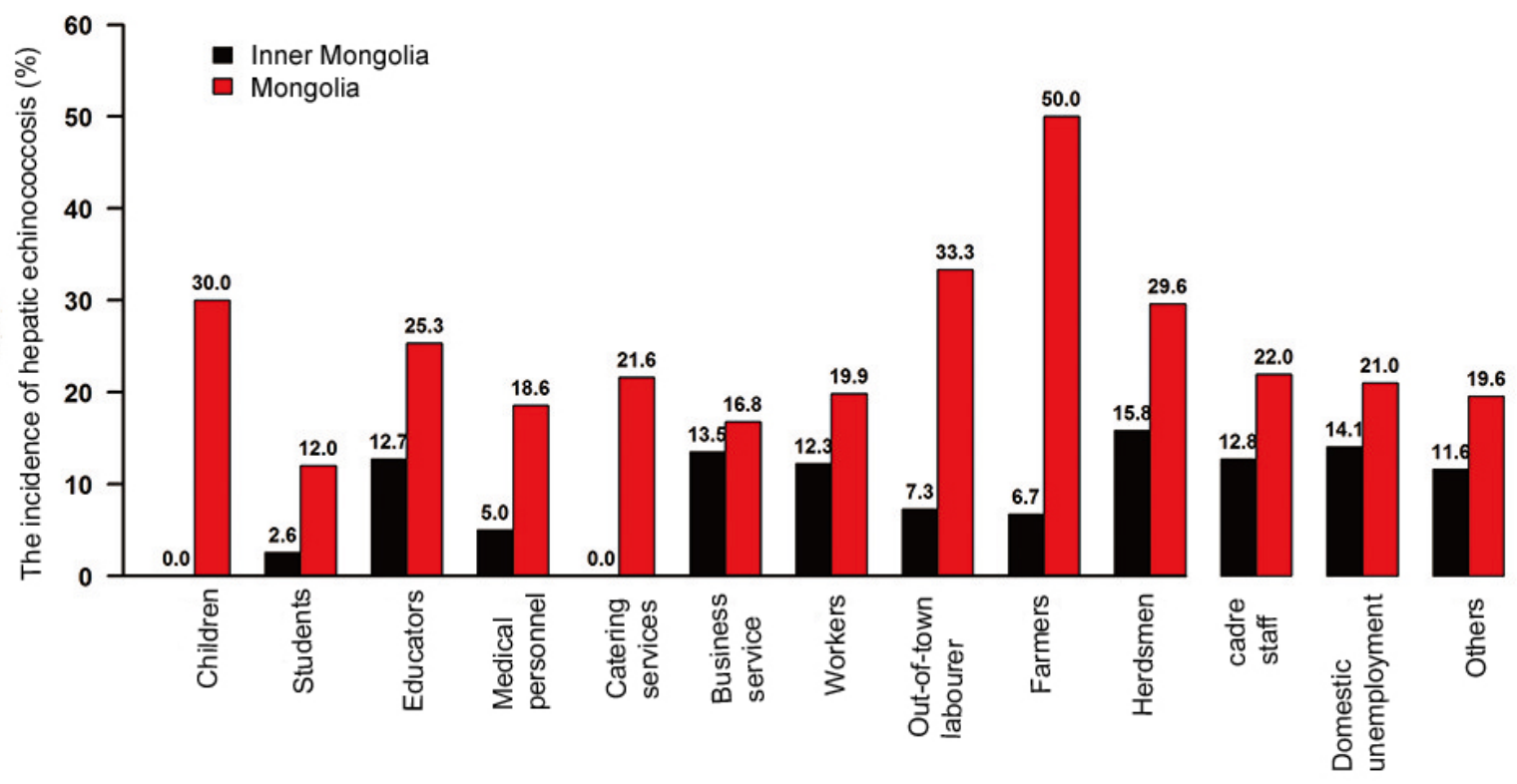

Figure 1. The incidence of hepatic echinococcosis in different professions

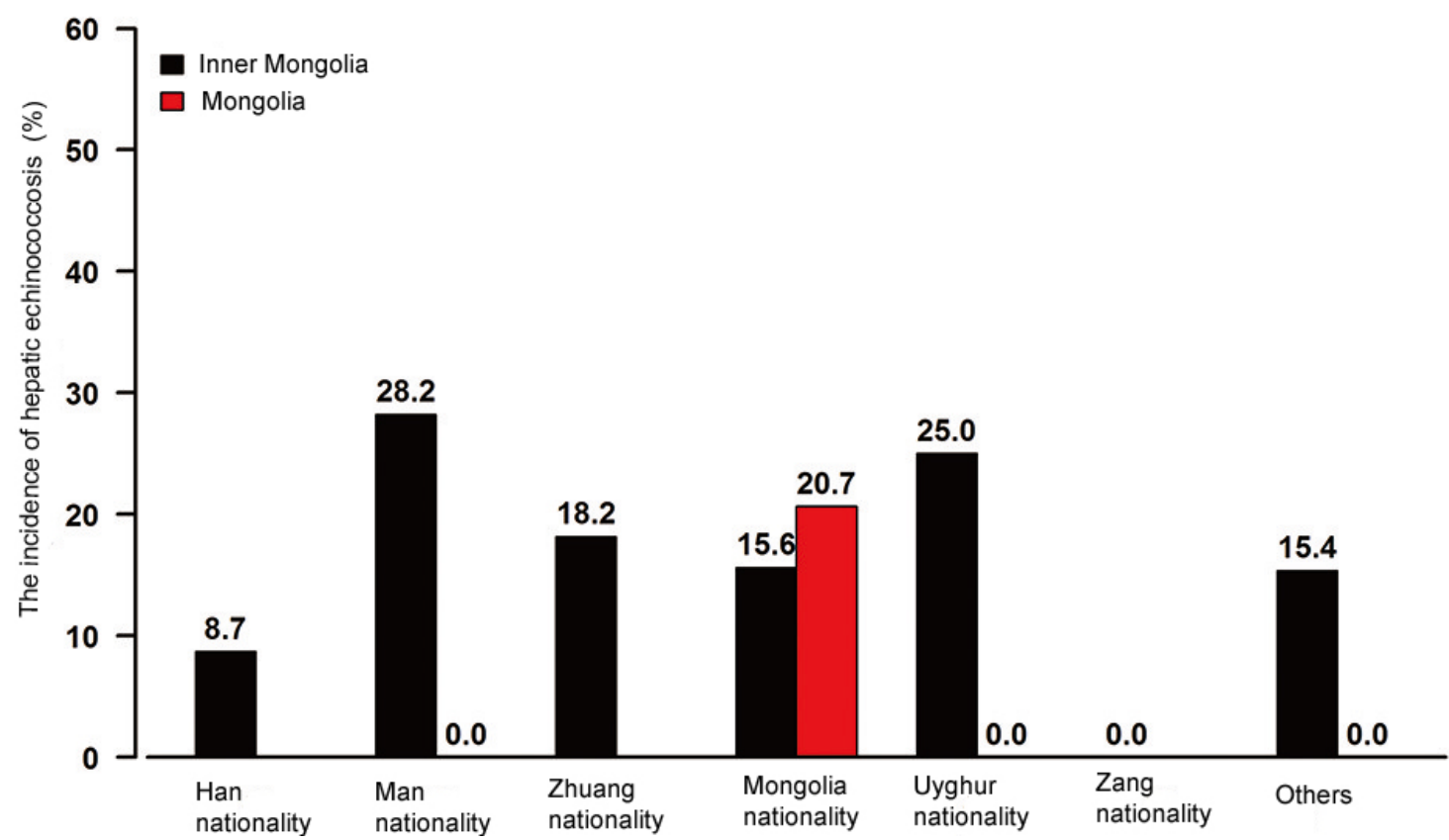

Figure 2. The incidence of hepatic echinococcosis in different nationalities 
Table 3. The results of overall univariate analysis

\begin{tabular}{|c|c|c|c|c|c|}
\hline Variate & Negative (\%) & Positive (\%) & Total & Statistics & $p$ \\
\hline Age & $52.80 \pm 13.88$ & $53.31 \pm 14.01$ & $52.86 \pm 13.90$ & -1.182 & .237 \\
\hline \multicolumn{6}{|l|}{ Gender } \\
\hline Male & 3,279 (89.1) & $400(10.9)$ & 3,679 & \multirow[t]{2}{*}{28.194} & \multirow[t]{2}{*}{$<.001$} \\
\hline Female & $4,395(85.3)$ & $760(14.7)$ & 5,155 & & \\
\hline \multicolumn{6}{|l|}{ Degree of education } \\
\hline College degree or above & 1,731 (88.0) & $236(12.0)$ & 1,967 & \multirow[t]{5}{*}{38.768} & \multirow[t]{5}{*}{$<.001$} \\
\hline Senior school & $2,405(87.7)$ & $338(12.3)$ & 2,743 & & \\
\hline Junior school & $1,416(89.5)$ & $166(10.5)$ & 1,582 & & \\
\hline Elementary school & 1,043 (83.8) & $202(16.2)$ & 1,245 & & \\
\hline Illiteracy & $1,090(83.3)$ & $219(16.7)$ & 1,309 & & \\
\hline \multicolumn{6}{|l|}{ Living pattern } \\
\hline Settled & 7,309 (87.0) & $1,093(13.0)$ & 8,402 & 12.797 & .002 \\
\hline Nomadic & $182(79.5)$ & $47(20.5)$ & 229 & & \\
\hline Settled in winter and nomadic in summer & $157(90.2)$ & $17(9.8)$ & 174 & & \\
\hline Raising livestock & & & & & \\
\hline Yes & 4,480 (87.9) & $616(12.1)$ & 5,096 & 13.115 & $<.001$ \\
\hline No & $3,135(85.3)$ & $542(14.7)$ & 3,677 & & \\
\hline Livestock slaughter manner & & & & & \\
\hline Domestic slaughter & $2,927(85.7)$ & $489(14.3)$ & 3,416 & & \\
\hline Past medical examination for echinococc & & & & & \\
\hline Yes & 739 (88.6) & $95(11.4)$ & 834 & 2.387 & .122 \\
\hline No & $6,930(86.7)$ & $1,062(13.3)$ & 7,992 & & \\
\hline Living in pastoral areas & & & & & \\
\hline Yes & 3,818 (87.3) & 557 (12.7) & 4,375 & 1.406 & .236 \\
\hline No & $3,868(86.4)$ & $608(13.6)$ & 4,476 & & \\
\hline Having been to pastoral areas & & & & & \\
\hline Yes & 4,703 (86.6) & $726(13.4)$ & 5,429 & 0.496 & .481 \\
\hline No & $2,970(87.1)$ & $438(12.9)$ & 3,408 & & \\
\hline Contacting with dogs in the pastoral are & & & & & \\
\hline None & $4,345(88.5)$ & $567(11.5)$ & 4,912 & 29.316 & $<.001$ \\
\hline Occasionally & $2,414(85.5)$ & $409(14.5)$ & 2,823 & & \\
\hline Closely & $929(83.1)$ & $189(16.9)$ & 1,118 & & \\
\hline $\begin{array}{l}\text { Eating uncooked food and drinking un } \\
\text { the pastoral area }\end{array}$ & & & & & \\
\hline None & $4,942(87.4)$ & $711(12.6)$ & 5,653 & 3.107 & .078 \\
\hline Yes & $2,688(86.1)$ & $434(13.9)$ & 3,122 & & \\
\hline Whether the neighborhood were raising & & & & & \\
\hline No & 3,047 (87.7) & 426 (12.3) & 3,473 & 6.204 & .045 \\
\hline Some & $4,326(86.5)$ & $677(13.5)$ & 5,003 & & \\
\hline Nearly all & $314(83.7)$ & $61(16.3)$ & 375 & & \\
\hline Having fox furs & & & & & \\
\hline None & $6,598(87.7)$ & $929(12.3)$ & 7,527 & 18.360 & $<.001$ \\
\hline Yes & $852(82.9)$ & $176(17.1)$ & 1,028 & & \\
\hline Surrounding activities of foxes and voles & & & & & \\
\hline None & $4,705(87.1)$ & $697(12.9)$ & 5,402 & 0.759 & .384 \\
\hline Existed & $2,942(86.5)$ & 461 (13.5) & 3,403 & & \\
\hline Source of water & & & & & \\
\hline gutterway & $27(90.0)$ & $3(10.0)$ & 30 & 1.666 & .948 \\
\hline River & $34(85.0)$ & $6(15.0)$ & 40 & & \\
\hline Well & $3,103(86.6)$ & $479(13.4)$ & 3,582 & & \\
\hline Pond & $7(87.5)$ & $1(12.5)$ & 8 & & \\
\hline Pool & $2(100.0)$ & $0(0.0)$ & 2 & & \\
\hline Spring & $5(100.0)$ & $0(0.0)$ & 5 & & \\
\hline Running water & $4,513(87.0)$ & $676(13.0)$ & 5,189 & & \\
\hline Whether had hepatic echinococcosis befo & & & & & \\
\hline Yes & $8(80.0)$ & $2(20.0)$ & 10 & 0.422 & .516 \\
\hline No & 7,595 (86.9) & $1,142(13.1)$ & 8,737 & & \\
\hline Past medical therapy & & & & & \\
\hline Medication & $66(82.5)$ & $14(17.5)$ & 80 & 0.977 & .323 \\
\hline Surgery & $4,560(86.3)$ & $722(13.7)$ & 5,282 & & \\
\hline Disposal method of offals after the sl & & & & & \\
\hline livestock & & & & & \\
\hline Abandoned & $6,158(87.9)$ & $849(12.1)$ & 7,007 & 52.202 & $<.001$ \\
\hline Human consumption & $472(87.6)$ & $67(12.4)$ & 539 & & \\
\hline Feeding dogs & $747(81.0)$ & $175(19.0)$ & 922 & & \\
\hline Buried or burned & $220(78.3)$ & $61(21.7)$ & 281 & & \\
\hline Hand-washing when eating food & & & & & \\
\hline Seldom & $2,750(86.6)$ & $426(13.4)$ & 3,176 & 10.330 & .006 \\
\hline Sometimes & $4,631(86.7)$ & $713(13.3)$ & 5,344 & & \\
\hline Often & $297(92.8)$ & $23(7.2)$ & 320 & & \\
\hline Playing with a dog & & & & & \\
\hline Never & $504(89.2)$ & $61(10.8)$ & 565 & 8.319 & .016 \\
\hline
\end{tabular}


Table 4. The results of stratified univariate analysis

\begin{tabular}{|c|c|c|c|c|c|c|}
\hline \multirow{2}{*}{ Variate } & \multicolumn{3}{|c|}{ Inner Mongolia } & \multicolumn{3}{|c|}{ Mongolia } \\
\hline & Negative (\%) & Positive (\%) & $p$ value & Negative (\%) & Positive (\%) & $p$ value \\
\hline Age & $54.65 \pm 13.12$ & $56.53 \pm 12.24$ & $<.001$ & $42.58 \pm 13.53$ & $44.25 \pm 14.70$ & .060 \\
\hline \multicolumn{7}{|l|}{ Gender } \\
\hline Male & 2,830 (90.2) & 309 (9.8) & \multirow[t]{2}{*}{$<.001$} & 449 (83.1) & $91(16.9)$ & \multirow[t]{2}{*}{.007} \\
\hline Female & 3,672 (87.0) & $547(13.0)$ & & $723(77.2)$ & $213(22.8)$ & \\
\hline Degree of education & & & & & & \\
\hline College degree or above & $1,723(88.0)$ & $235(12.0)$ & .416 & $8(88.9)$ & $1(11.1)$ & .721 \\
\hline Senior school & 2,373 (87.8) & $330(12.2)$ & & $32(80.0)$ & $8(20.0)$ & \\
\hline Junior school & 1,375 (89.6) & $159(10.4)$ & & $41(85.4)$ & $7(14.6)$ & \\
\hline Elementary school & $610(88.2)$ & $82(11.8)$ & & 433 (78.3) & $120(21.7)$ & \\
\hline Illiteracy & $424(89.3)$ & $51(10.7)$ & & 666 (79.9) & $168(20.1)$ & \\
\hline Living pattern & & & & & & \\
\hline Settled & 6,225 (88.5) & 812 (11.5) & .003 & 1,084 (79.4) & 281 (20.6) & .855 \\
\hline Nomadic & $93(78.8)$ & $25(21.2)$ & & $89(80.2)$ & $22(19.8)$ & \\
\hline Settled in winter and nomadic in summer & $152(91.0)$ & $15(9.0)$ & & $5(71.4)$ & $2(28.6)$ & \\
\hline Raising livestock & & & & & & \\
\hline Yes & 4,295 (88.6) & 555 (11.4) & .335 & $185(75.2)$ & $61(24.8)$ & .080 \\
\hline No & $2,157(87.8)$ & $300(12.2)$ & & $978(80.2)$ & $242(19.8)$ & \\
\hline Livestock slaughter manner & & & & & & \\
\hline Centralized slaughter & $821(93.1)$ & $61(6.9)$ & $<.001$ & $40(87.0)$ & $6(13.0)$ & .174 \\
\hline Sporadic slaughter & $656(94.3)$ & $40(5.7)$ & & 73 (73.7) & $26(26.3)$ & \\
\hline Domestic slaughter & 2,831 (86.1) & $456(13.9)$ & & $96(74.4)$ & $33(25.6)$ & \\
\hline Past medical examination for echinococc & & & & & & \\
\hline Yes & 723 (88.9) & $90(11.1)$ & .576 & $16(76.2)$ & $5(23.8)$ & .691 \\
\hline No & $5,775(88.3)$ & $768(11.7)$ & & 1,155 (79.7) & $294(20.3)$ & \\
\hline Living in pastoral areas & & & & & & \\
\hline Yes & $3,728(87.5)$ & 535 (12.5) & .006 & $90(80.4)$ & $22(19.6)$ & .810 \\
\hline No & $2,777(89.5)$ & $325(10.5)$ & & $1,091(79.4)$ & $283(20.6)$ & \\
\hline Having been to pastoral areas & & & & & & \\
\hline Yes & 4,345 (87.3) & $630(12.7)$ & $<.001$ & 358 (78.9) & $96(21.1)$ & .694 \\
\hline No & $2,147(90.4)$ & $229(9.6)$ & & $823(79.7)$ & $209(20.3)$ & \\
\hline Contacting with dogs in the pastoral area & & & & & & \\
\hline None & $3,625(90.4)$ & $387(9.6)$ & $<.001$ & $720(80.0)$ & $180(20.0)$ & .813 \\
\hline Occasionally & $1,995(87.1)$ & 296 (12.9) & & 419 (78.8) & $113(21.2)$ & \\
\hline Closely & $887(83.4)$ & $177(16.6)$ & & $42(77.8)$ & $12(22.2)$ & \\
\hline $\begin{array}{l}\text { Eating uncooked food and drinking unt } \\
\text { water in the pastoral area }\end{array}$ & & & & & & \\
\hline None & 3,958 (89.9) & $446(10.1)$ & $<.001$ & 984 (78.8) & $265(21.2)$ & .137 \\
\hline Yes & $2,492(86.3)$ & $394(13.7)$ & & $196(83.1)$ & $40(16.9)$ & \\
\hline Raising dogs & & & & & & \\
\hline Yes & 2,768 (86.9) & $416(13.1)$ & $<.001$ & $413(82.3)$ & $89(17.7)$ & .055 \\
\hline No & 3,736 (89.4) & $442(10.6)$ & & 759 (78.0) & $214(22.0)$ & \\
\hline Whether the neighborhood were raising & & & & & & \\
\hline No & 2,489 (90.1) & $273(9.9)$ & $<.001$ & 558 (78.5) & $153(21.5)$ & .670 \\
\hline Some & $3,792(87.4)$ & $547(12.6)$ & & $534(80.4)$ & $130(19.6)$ & \\
\hline Nearly all & $227(85.3)$ & $39(14.7)$ & & $87(79.8)$ & $22(20.2)$ & \\
\hline Having fox furs & & & & & & \\
\hline None & $5,699(89.2)$ & $692(10.8)$ & $<.001$ & 899 (79.1) & 237 (20.9) & .664 \\
\hline Yes & $731(83.3)$ & $147(16.7)$ & & $121(80.7)$ & 29 (19.3) & \\
\hline Surrounding activities of foxes and voles & & & & & & \\
\hline None & 3,591 (89.7) & $414(10.3)$ & $<.001$ & 1,114 (79.7) & $283(20.3)$ & .094 \\
\hline Yes & $2,892(86.8)$ & $441(13.2)$ & & $50(71.4)$ & $20(28.6)$ & \\
\hline Source of water & & & & & & \\
\hline gutterway & $26(92.9)$ & $2(7.1)$ & .955 & $1(50.0)$ & $1(50.0)$ & .673 \\
\hline River & $27(87.1)$ & $4(12.9)$ & & $7(77.8)$ & $2(22.2)$ & \\
\hline Well & $2,554(88.2)$ & $342(11.8)$ & & $549(80.0)$ & $137(20.0)$ & \\
\hline Pond & $5(83.3)$ & $1(16.7)$ & & $2(100.0)$ & $0(0.0)$ & \\
\hline Pool & $2(100.0)$ & $0(0.0)$ & & - & - & \\
\hline Spring & - & - & & $5(100.0)$ & $0(0.0)$ & \\
\hline Running water & 3,896 (88.4) & $511(11.6)$ & & $617(78.9)$ & $165(21.1)$ & \\
\hline Whether had hepatic echinococcosis befo & & & & & & \\
\hline Yes & $1(100.0)$ & $0(0.0)$ & .717 & $7(77.8)$ & $2(22.2)$ & .900 \\
\hline No & $6,476(88.4)$ & $853(11.6)$ & & $1,119(79.5)$ & 289 (20.5) & \\
\hline Past medical therapy & & & & & & \\
\hline Medication & $9(100.0)$ & $0(0.0)$ & .238 & $57(80.3)$ & $14(19.7)$ & .842 \\
\hline Surgery & $4,325(86.6)$ & $668(13.4)$ & & $235(81.3)$ & $54(18.7)$ & \\
\hline $\begin{array}{l}\text { Disposal method of offals after the slaugh } \\
\text { sick livestock }\end{array}$ & & & & & & \\
\hline Abandoned & $5,855(88.3)$ & $775(11.7)$ & .037 & $303(80.4)$ & $74(19.6)$ & .129 \\
\hline Human consumption & $355(91.5)$ & $33(8.5)$ & & 117 (77.5) & $34(22.5)$ & \\
\hline Feeding dogs & $71(85.5)$ & $12(14.5)$ & & $676(80.6)$ & $163(19.4)$ & \\
\hline Buried or burned & $134(83.2)$ & $27(16.8)$ & & $86(71.7)$ & $34(28.3)$ & \\
\hline Hand-washing when eating food & & & & & & \\
\hline Seldom & $1,872(90.4)$ & $199(9.6)$ & $<.001$ & 878 (79.5) & 227 (20.5) & .620 \\
\hline Sometimes & $4,352(87.2)$ & $640(12.8)$ & & 279 (79.3) & $73(20.7)$ & \\
\hline Often & $276(93.2)$ & $20(6.8)$ & & $21(87.5)$ & $3(12.5)$ & \\
\hline Playing with a dog & & & & & & \\
\hline Never & $404(92.2)$ & $34(7.8)$ & .022 & 100 (78.7) & $27(21.3)$ & .791 \\
\hline Occasionally & $4,788(88.3)$ & $637(11.7)$ & & $420(80.5)$ & $102(19.5)$ & \\
\hline Often & $1,184(89.6)$ & $137(10.4)$ & & $662(79.0)$ & $176(21.0)$ & \\
\hline
\end{tabular}


The stratified analysis of data from Inner Mongolia and Mongolia was shown in Table 4. Because of the limited number of survey data in Mongolia, it was only concluded that the positive rate in the female was significantly higher than that in the males, and there was no statistically significant difference in the comparison of the positive rates between different risk behaviors. The results of statistical analysis towards Inner Mongolia showed that the age of the patients with positive results was obviously higher than that of the patients with negative results (differing by 2 years old). There was no statistically significant difference in the degree of education. In addition, it was found that living in pastoral areas, having been to pastoral areas, eating uncooked food and drinking unboiled water in the pastoral area, raising dogs and surrounding activities of foxes and voles could increase the risk of positivity. Other results conformed to the overall analytic results.

Table 5. The results of multivariable analysis

\begin{tabular}{|c|c|c|c|c|c|c|c|c|c|}
\hline \multirow{2}{*}{ Variate } & \multicolumn{3}{|c|}{ Overall } & \multicolumn{3}{|c|}{ Inner Mongolia } & \multicolumn{3}{|c|}{ Mongolia } \\
\hline & OR & $95 \% \mathrm{CI}$ & $p$ value & OR & $95 \% \mathrm{CI}$ & $p$ value & OR & $95 \% \mathrm{CI}$ & $p$ value \\
\hline Age & 1.01 & $1.00-1.02$ & .034 & & & & & & \\
\hline Female & 1.56 & $1.29-1.89$ & .000 & 1.45 & $1.19-1.77$ & .000 & 2.06 & $1.04-4.10$ & .039 \\
\hline \multicolumn{10}{|l|}{$\begin{array}{l}\text { Disposal method of offals after the } \\
\text { slaughter of sick livestock }\end{array}$} \\
\hline Abandoned & 1.00 & & & & & & & & \\
\hline Human consumption & 0.73 & $0.46-1.15$ & .176 & 0.70 & $0.43-1.13$ & .146 & & & \\
\hline Feeding dogs & 2.02 & $1.28-3.20$ & .003 & 1.80 & $0.87-3.73$ & .115 & & & \\
\hline Buried or burned & 1.76 & $1.09-2.85$ & .022 & 2.13 & $1.24-3.65$ & .006 & & & \\
\hline $\begin{array}{l}\text { No past medical examination for } \\
\text { echinococcosis }\end{array}$ & 1.62 & $1.20-2.20$ & .002 & 1.73 & $1.28-2.34$ & .000 & & & \\
\hline \multicolumn{10}{|l|}{ Contacting with dogs in the pastoral area } \\
\hline None & 1.00 & & & & & & & & \\
\hline Occasionally & 1.28 & $0.98-1.67$ & .069 & & & & & & \\
\hline Closely & 1.52 & $1.13-2.03$ & .005 & & & & & & \\
\hline \multicolumn{10}{|l|}{ Degree of education } \\
\hline College degree or above & 1.00 & & & & & & & & \\
\hline Senior school & 1.19 & $0.94-1.51$ & .152 & & & & & & \\
\hline Junior school & 1.01 & $0.73-1.38$ & .974 & & & & & & \\
\hline Elementary school & 1.66 & $1.12-2.46$ & .012 & & & & & & \\
\hline Illiteracy & 2.15 & $1.31-3.53$ & .003 & & & & & & \\
\hline Having fox furs & 1.45 & $1.08-1.95$ & .012 & 1.47 & $1.07 \sim 2.01$ & .016 & & & \\
\hline \multicolumn{10}{|l|}{ Livestock slaughter manner } \\
\hline Centralized slaughter & 1.00 & & & & & & & & \\
\hline Sporadic slaughter & 0.83 & $0.55-1.24$ & .362 & 0.54 & $0.34-0.87$ & .011 & & & \\
\hline Domestic slaughter & 2.08 & $1.53-2.81$ & .000 & 2.13 & $1.55-2.92$ & .000 & & & \\
\hline Living in pastoral areas & & & & 2.68 & $2.04-3.52$ & .000 & & & \\
\hline \multicolumn{10}{|l|}{ Living pattern } \\
\hline Settled & 1.00 & & & & & & & & \\
\hline Nomadic & 2.20 & $1.28-3.77$ & .004 & 2.20 & $1.18-4.10$ & .013 & & & \\
\hline Settled in winter and nomadic in summer & 0.52 & $0.29-0.93$ & .027 & 0.45 & $0.25-0.82$ & .009 & & & \\
\hline Surrounding activities of foxes and voles & & & & 1.46 & $1.17-1.83$ & .001 & & & \\
\hline \multicolumn{10}{|l|}{ Hand-washing when eating food } \\
\hline Seldom & 1.00 & & & & & & & & \\
\hline Sometimes & 1.36 & $1.09-1.69$ & .006 & 1.54 & $1.21-1.95$ & .000 & & & \\
\hline Often & 0.59 & $0.31-1.13$ & .111 & 0.72 & $0.38-1.37$ & .314 & & & \\
\hline Having been to pastoral areas & 1.58 & $1.17-2.14$ & .003 & & & & & & \\
\hline
\end{tabular}




\subsection{Multivariate analysis}

Backward-stepwise regression was applied to multivariate analysis. Excluding nationality and profession, all variates in the above univariate analysis were considered as candidate variates. Our team believed that nationality and profession can increase the risk of positivity through other related risk behaviors. Nationality and profession were so closely related with other risk behaviors that they would not be integrated in multivariate analysis. Table 5 showed the results of multivariate stratified analysis. Due to the small amount of samples in Mongolia, the results of multivariate analysis were consistent with the results of univariate analysis, and the only finding was that the female had a higher risk of hepatic echinococcosis than the male. Meanwhile, in Inner Mongolia, the results showed that living in pastoral areas, surrounding activities of foxes and voles would increase the risk of positivity, and age, contacting with dogs in the pastoral area, degree of education and having been to pastoral areas were no longer the risk factors for echinococcosis.

\section{Discussion}

Echinococcosis is generally spread in the biological chain of livestock (intermediate host) to dogs (definitive host), and it is the most harmful parasitosis to people and livestock in the pastoral and farming-pastoral areas. This type of disease not only affects the health of local population in an intensified degree, but also extremely damages the development of animal husbandry in the epidemic area. Based on the large-sample data of sampling survey from Inner Mongolia and Mongolia, this research is designed to analyze the related risk factors for hepatic echinococcosis. Both univariate analysis and multivariate analysis show that the female has a higher risk of hepatic echinococcosis than the male. No past medical examination for echinococcosis, having fox furs, seldom washing hands when eating food, domestic slaughter of livestock, burying or burning offals after slaughtering sick livestock or feeding dogs with them and nomadic lifestyle are independent risk factors for hepatic echinococcosis.

\subsection{The correlation of gender to the incidence of hepatic echinococcosis}

Ying D et al. ${ }^{[10]}$ found that in their epidemiological study of hepatic echinococcosis, the female had a higher incidence than the male, which was also identified in our epidemiological study. According to the analysis, the main cause may be that it was the female who was engaged in housework in the agricultural and the pastoral areas, such as feeding dogs and livestock, milking, picking up shards and so on, i.e., the female came into contact with dogs, livestock or their feces, so that they had more exposure to the eggs of echinococcus than the male, leading to the highest rate of hepatic echinococcosis in the female.

\subsection{The correlation of lifestyle to the incidence of hep- atic echinococcosis}

The survey showed that having fox furs, seldom washing hands when eating food, domestic slaughter of livestock, burying or burning offals after slaughtering sick livestock or feeding dogs with them and nomadic lifestyle are independent risk factors for hepatic echinococcosis. Residents in the agricultural and the pastoral areas hunt foxes and kill them for their furs without proper disinfection, so that the infection rate is increased eventually. Eating uncooked meat and seldom washing hands when eating food make herdsmen have a higher risk for the infection of echinococcus. Most of families prefer domestic slaughter of livestock and feed dogs with offals of sick livestock, leading to the aggravation of vicious circle in the infection of echinococcosis.

\section{Conclusions}

Hepatic echinococcosis is highly prevalent in Inner Mongolia of China and Mongolia, and the female is the risk population. It is recommended to avoid domestic slaughter, the usage of fox furs and burying or burning offals of sick livestock or feeding dogs with them.

\section{FINANCIAL SUPPORT}

The research was supported by Program of International S\&T Cooperation (No.2011DFA32740).

\section{CONFlicts of InTEREST Disclosure}

The authors declare they have no conflicts of interest.

\section{REFERENCES}

[1] Brunetti E, Kern P, Vuitton DA. Writing panel for the W-I. expert consensus for the diagnosis and treatment of cystic and alveolar echinococcosis in humans. Acta tropica. 2010; 114(1): 1-16. PMid:19931502. https://doi.org/10.1016/j.actatropica.
2009.11.001

[2] Ju Y, Tianci L. Progress on the epidemiological study of echinococcosis. Ningxia Medical Journal. 2008; 30(4): 378-379.

[3] Xiang X, Weiping W. Progress on research of prevalent factors of echinococcosis. International Journal of Medical Parasitic Diseases. 
2007; 34(5): 262-265

[4] Bo T, Bin Z, Baobiao D. Epidemiological study and control effect on echinococcosis in Inner Mongolia. Chinese Journal of Zoonoses. 2011; 27(7): 677-678.

[5] Bo R, Hao W, Tuergan•aili, et al. The efficacy of various managements of indurative biliary fistula after hepatic cystic echinococcosis (HCE) operation. Chinese Journal of Hepatobiliary Surgery. 2013; 19(4): 275-277.

[6] Zhihua Y, Xinmin W, Ronghua M, et al. Heptic alveolar echinococcosis in the terminal stage of liver autotransplantation treatment in the plateau area. Chinese Journal of Hepatobiliary Surgery. 2014; 20(2): 148-150.
[7] Dazhong S, Wenke L, Genshu B. Approach to risk factor of human behavior on epidemic of alveolar echinococcosis. Chinese Journal of Public Health. 2003; 19(8): 973-974.

[8] Li L. An epidemiologic study on the echinococcosis of residents in rural areas of Ningxia Hui Autonomous Region. Epidemiology and Health Statistics, Shanxi Medical University, 2007.

[9] $\mathrm{Hu}$ W. Analysis on risk factors of human hydatidosis in Qinhai Province. Chinese Journal of Parasitic Disease Control. 2004; 17(4): 214-216.

[10] Ying D, Tianpeng L, et al. Analysis of prevalent status of hydatid disease in Yunnan Province and affecting factors. China Tropical Medicine. 2006; 6(1): 1773-1774. 